\title{
Study of spindle drives for boring machines
}

\author{
Marin Zhilevski ${ }^{1, *}$ and Mikho Mikhov ${ }^{1}$ \\ ${ }^{1}$ Faculty of Automatics, Technical University of Sofia, Bulgaria
}

\begin{abstract}
This paper examines the main requirements for the electric drive systems of a class of boring machines with digital program control. On this basis, a methodology for choice of the spindle drives is offered. The algorithm takes into account the specific features of the technological processes, the treated materials, the tools used and their wear, as well as the mechanical gear types. The experimental studies of the implemented electric drives for the spindle are presented and discussed. The research carried out and the results obtained can be used in the development of such drives for the studied class of machine tools.
\end{abstract}

\section{Introduction}

Boring machines are usually used to mill, drill, bore, cut threads or face turn. They can be horizontal or vertical, which refers to the orientation of the axis using a rotating tool of the machine spindle that provides the primary motion. These machines allow to achieve greater accuracy of the diameter of holes, and use a cutter, drill, boring rod or milling head to drill closed and open openings in solid material, boring, reaming, threading, milling surfaces, etc. [1-5].

The drive system for boring machines includes feed drives, spindle drive and auxiliary drives. For modernization of a type of boring machines with digital program control, two additional controlled axes for angular position are introduced, as well as a device that provides solid positioning over 30 degrees of the workpieces. The aim is to extend the capabilities of these machines to process more complex machine parts and to enhance their performance. In this way, the machines under consideration can be referred to those with multicoordinate electric driving systems.

An approach to optimal selection of feed drives for boring machines is presented in [6].

The spindle electric drives are involved in the machining process, significantly affecting the quality of the parts and their productivity [7, 8]. In these drives the speed regulation is carried out at constant motor torque until a basic value is reached. After that, it is done at constant power. A distinctive feature of the dual-zone speed control is that the system structure changes along the process of regulation and the optimal coordination of the zones creates the main control problem.

Mathematical modeling and computer simulation offer effective ways to study the electric drive systems in details for various dynamic and static working regimes, especially when it is not possible or it is inconvenient to carry out such tests in laboratory or industrial environments. With the MATLAB/SIMULINK software package, a number of computer simulation models have been developed to analyze the respective control algorithms in drive systems with dual-zone speed regulation.

In $[9,10]$ are presented technical possibilities and mathematical models for kinematic system diagnostics of machine tools. In [11] a DC electric drive system with dual-zone speed regulation is presented, where control shift is a function of the motor back EMF voltage. Using an appropriate vector-matrix description of the controlled object, in [12] an optimal modal speed controller for the first zone is synthesized, as well as an adaptive optimal modal controller of the back EMF voltage for the second speed zone. To improve the electric drive performance an adaptive speed controller with switchable structure is developed [13]. In the second zone, the controller parameters adapt to the decreasing magnetic flux. Such an approach provides for better static and dynamic characteristics of the driving system.

Nowadays, spindle drives with AC motors are used applying vector control $[14,15]$. The main advantage of such electric drives relates to the easier maintenance of the AC motors because they are brushless.

In this paper, the main features for the respective drives of a type of boring machines with digital program control are formulated and on this basis, a methodology for selection of spindle electric drives is developed. In choosing suitable spindle drives, a number of essential factors were taken into account, namely: the technological process features, the processed materials, the tools used and the mechanical gears. Some dual-zone spindle drives with DC and AC motors are presented, illustrating the practical application of the offered approach. Experimental studies of the implemented drives related for the spindle are presented and discussed.

\section{Features of the drive system}

The simplified block diagram of the drive system for a studied class of boring machines is shown in Fig. 1, where the following notations are used: DPC - digital

*Corresponding author: mzhilevski@tu-sofia.bg 
program control device; ED1 - ED10 - electric drives; G1 - G8 - mechanical gears; L1 - L8 - loads. Each of the presented drive subsystems has specific features and requirements that need to be taken into account in the process of design, study and practical application.

The feed drives of the $x, y, z, a$, and $c$ coordinate axes are used for positioning of the tool and the workpiece at the desired locations and they participate in the machining process. The main requirements for them can be formulated as follows:

- smooth speed regulation in a wide range;

- good dynamics;

- high position accuracy;

- formation of the necessary position cycles;

- providing the required torque;

- reversible speed and torque control;

- compensation of the disturbances;

- easy maintenance;

- reliability;

- economy.

The spindle drive is involved in the machining process and it should meet the following requirements:

- dual-zone speed regulation (by constant torque and constant power, respectively);

- high maximum speed;

- sufficient torque;

- oriented braking with high accuracy;

- reversible speed control.

The main requirements for the auxiliary drives can be formulated as follows:

- solid angular positioning of the workpiece with high precision;

- a subsystem providing choice of the desired tool;

- dosing lubrication of the machine coordinate axes;

- cooling subsystem with option for automatic and manual braking and starting from the control panel in order to reduce energy consumption.

The system for choice of instruments from the auxiliary drives relates to the spindle drive in the studied type of boring machines.

The development of appropriate spindle electric drives includes selection of motors, power converters, sensors, controllers and mechanical gears. This problem is very important in terms of performance, technoeconomic parameters, reliability, etc.

\section{Selection of spindle drives}

The design of spindle electric drives for boring machines includes the following stages:

- development of a methodology for optimal choice of dual-zone speed drives;

- performing calculations, according to the respective procedures of the methodology;

- technical and economic analysis of the possible types of electric drives, taking into account the catalog data;

- modeling and computer simulation of the relevant dynamic and static modes of operation;

- development of a stand for experimental studies;
- experimental determination of the necessary parameters for modeling;

- optimization and tuning of the respective control loops;

- computer simulation with various settings of the control loops to verify the used control algorithms;

- detailed experimental study to evaluate the actual performance of the drive system.

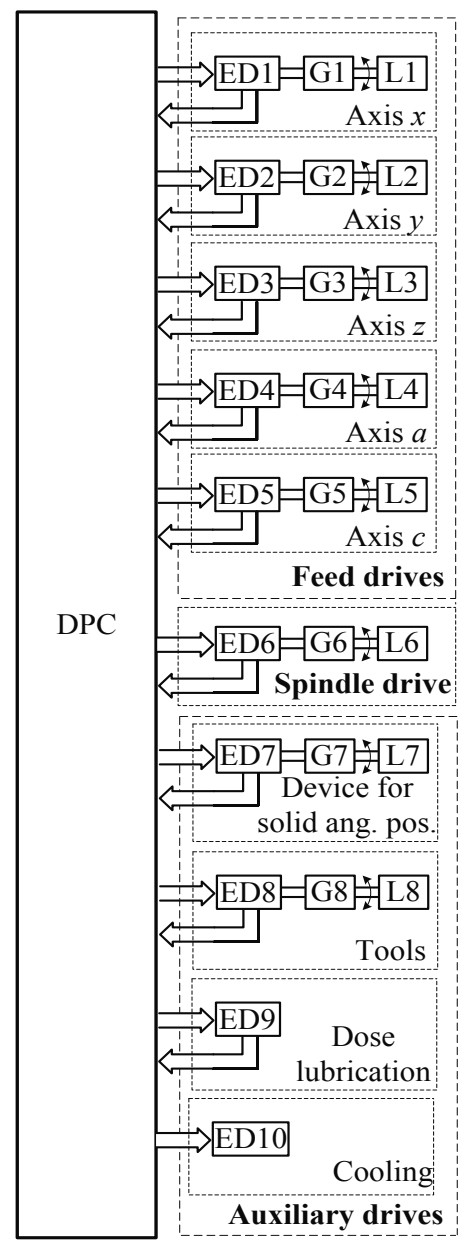

Fig. 1. Block diagram of the drive system.

\subsection{Methodology algorithm}

When choosing an electric drive, it is essential to define the heaviest processing mode of operation for the machine to optimize the power, speed and the price.

Fig. 2 shows the simplified block diagram of the developed algorithm for selection of spindle drives for the studied boring machines.

The following notations are used in this section: $D_{m b \max }$ - maximum diameter of boring machine; $D_{c b \text { max }}$ - maximum diameter of boring tool; $H_{B}$ Brinell hardness of the processed material; $V_{c b}$ - cutting speed; $\omega_{b}-$ spindle speed in the cutting process; $V_{f b}-$ feed speed; $f_{r b}$ - feed per radian; $a_{p b \text { max }}-$ maximum cutting depth, which is the difference between the uncut and the cut hole radius; $K_{c f z b}$ - specific cutting force, 
when feeding the tool tooth; $\eta_{b}$ - efficiency of the boring machine; $P_{c b \max }-$ maximum power needed to perform cutting, distributed between both feed drive and spindle drive without taking into account the tool wear; $P_{c b w}$ - power needed to perform cutting, distributed between both feed drive and spindle drive with taking into account the tool wear; $\omega_{b m}-$ minimum speed, which is selected for spindle motor from catalogue data; $K_{s p g}$ - mechanical gear ratio of the spindle drive; $P_{s p b}$ - power required only for the spindle drive.

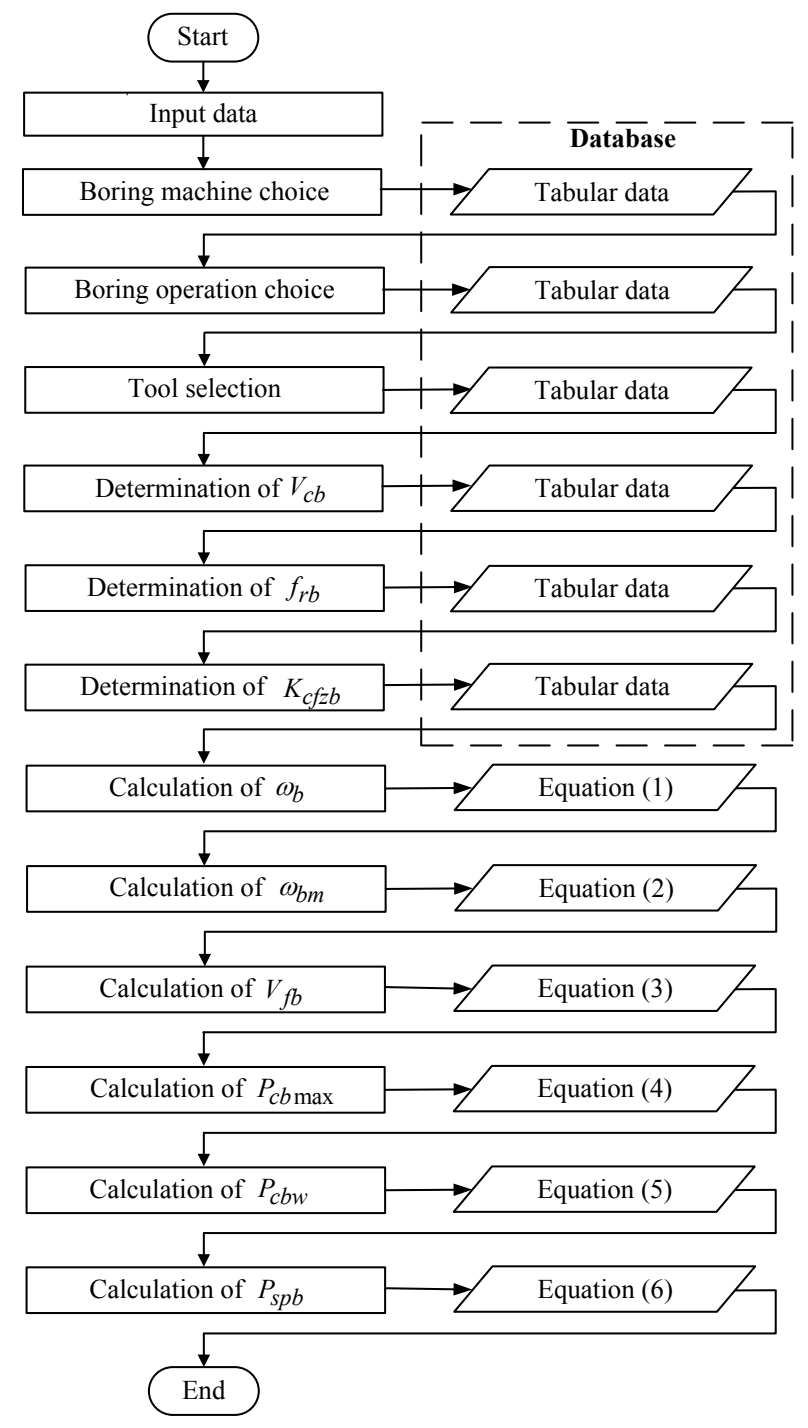

Fig. 2. Algorithm for selection of spindle drives.

The input data are as follows: the heaviest cutting regime, $H_{B}, D_{c b \text { max }}, D_{m b \text { max }}, a_{p b \max }, K_{s p g}$ and $\eta_{b}$. The tabular data used in this methodology are taken from [16].

The spindle speed in boring process is determined by the expression [16]:

$$
\omega_{b}=\frac{V_{c b} \times 2}{D_{m b \max }}
$$

Minimum speed, which is selected for the spindle motor:

$$
\omega_{b m}=\omega_{b} \times K_{s p g}
$$

The boring feed speed is calculated using the following equation [16]:

$$
V_{f b}=f_{r b} \times \omega_{b}
$$

The maximum power needed to perform boring process, distributed between both feed drive and spindle drive without taking into account the tool wear, is calculated by the next expression [16]:

$$
\begin{aligned}
& P_{c b \text { max }}=\frac{V_{c b} \times a_{p b \max } \times f_{r b} \times K_{c f z b} \times 2 \pi \times 10^{6}}{\eta_{b}} \times \\
& \times\left(1-\frac{a_{p b \max }}{D_{c b \text { max }}}\right)
\end{aligned}
$$

The maximum power needed to perform boring, distributed between both feed electric drive and spindle electric drive with taking into account the tool wear, is determined with the equation [16]:

$$
P_{c b w}=(1.1 \div 1.3) \times P_{c b \max }
$$

The power required only for the spindle drive is determined as follows [17]:

$$
P_{s p b}=(95 \div 99) \% \times P_{c b w}
$$

\subsection{Practical application}

The offered methodology for spindle drives selection takes into account the specific features of the technological processes, the processed materials, the tools used and their wear, as well as the mechanical gear coefficient. It gives opportunity for choice of motors, power converters and sensors.

Fig. 3 shows a diagram, illustrating the elements of some of the used electric drives for the studied machines. The notations used are as follows: DPC - digital program control device; 1 - position sensor for $z$ axis; 2 - motor for $z$ axis; 3 - coupling between the motor and the ball screw for $z$ axis; 4 - ball screw for $z$ axis; 5 guides for $z$ axis; 6 - speed sensor for the spindle drive; 7 - spindle motor; 8 - coupling between the spindle motor and gearbox; 9 - instruments drive; 10 - boring tool; 11 - position sensor for $x$ axis; 12 - motor for $x$ axis; 13 - coupling between the motor and the ball screw for $x$ axis; 14 - precision bearings for $x$ axis; 15 - driven mechanism (work desk for the workpiece); 16 processed workpiece; 17 - guides for $x$ axis; 18 - ball screw for $x$ axis; $h_{b_{x}}$ and $h_{b_{z}}$ - nominal steps of the ball screw for $x$ and $z$ axes; $D_{g b_{x}}$ and $D_{g b z}$ - nominal diameters of the mechanical gear made by a ball screw for $x$ and $z$ axes; $V_{b x}$ and $V_{b z}$ - speeds of the $x$ and $z$ axes; $F_{g x}$ and $F_{g z}$ - forces required for the guides of the 
$x$ and $z$ axes; $F_{f b z}$ - force for the feed drive in the cutting process of $z$ axis.

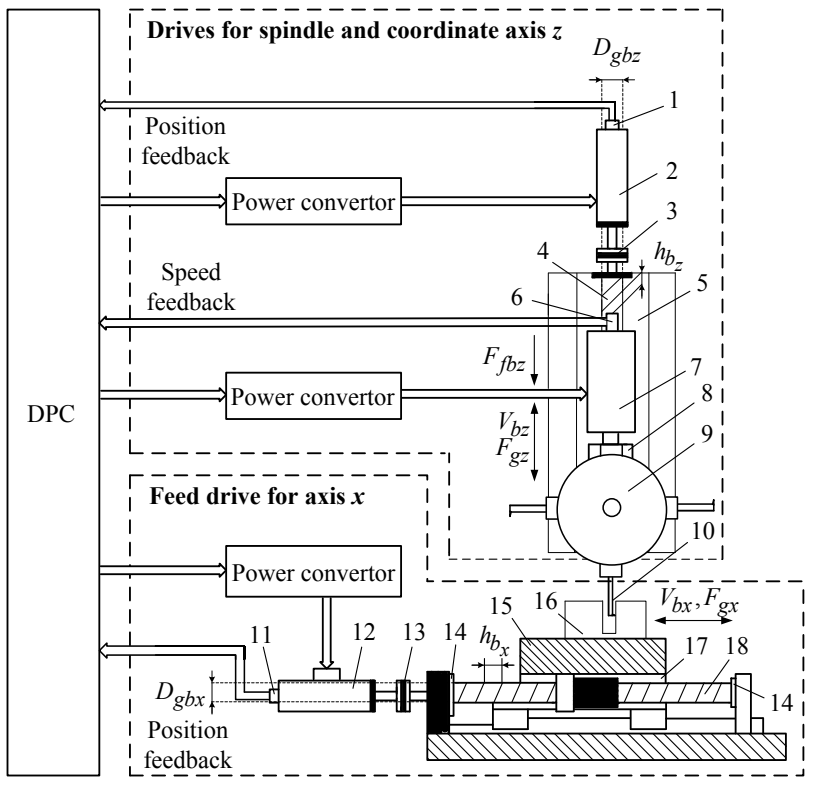

Fig. 3. Elements for some of the used electric drives.

Some examples of using this methodology for selection of spindle electric drive for cutting materials with different hardness are presented below.

Table 1. Results from the calculations.

\begin{tabular}{|c|c|c|c|}
\hline Step & Operation & Unalloyed steel & $\begin{array}{c}\text { Aluminium } \\
\text { alloys }\end{array}$ \\
\hline 1. & $\begin{array}{l}\text { Boring machine } \\
\text { choice }\end{array}$ & Vertical & Vertical \\
\hline 2. & $\begin{array}{c}\text { Boring } \\
\text { operation choice }\end{array}$ & $\begin{array}{l}\text { Multi-edge } \\
\text { boring }\end{array}$ & $\begin{array}{l}\text { Multi-edge } \\
\text { boring }\end{array}$ \\
\hline 3. & Tool selection & $\begin{array}{l}\text { Core } 820 \text { for } \\
\text { roughing }\end{array}$ & $\begin{array}{l}\text { Core } 820 \text { for } \\
\text { roughing }\end{array}$ \\
\hline 4. & $\begin{array}{l}\text { Determination } \\
\text { of } V_{c b}[\mathrm{~m} / \mathrm{s}]\end{array}$ & $\approx 3.67$ & $\approx 8.33$ \\
\hline 5. & $\begin{array}{l}\text { Determination } \\
\text { of } f_{r b}[\mathrm{~m} / \mathrm{rad}] \text {. }\end{array}$ & $3.1 \times 10^{-5}$ & $4.8 \times 10^{-5}$ \\
\hline 6. & $\begin{array}{c}\text { Determination } \\
\text { of } K_{c f z b}[\mathrm{MPa}] .\end{array}$ & 2000 & 500 \\
\hline 7. & $\begin{array}{l}\text { Calculation of } \\
\omega_{b}[\mathrm{rad} / \mathrm{s}]\end{array}$ & 146.8 & 333.2 \\
\hline 8. & $\begin{array}{l}\text { Calculation of } \\
\omega_{b m}[\mathrm{rad} / \mathrm{s}]\end{array}$ & 190.9 & 433.2 \\
\hline 9. & $\begin{array}{l}\text { Calculation of } \\
V_{f b}[\mathrm{~m} / \mathrm{s}]\end{array}$ & $4.55 \times 10^{-3}$ & $16 \times 10^{-3}$ \\
\hline 10 & $\begin{array}{l}\text { Calculation of } \\
P_{c b \max }[\mathrm{W}] .\end{array}$ & $\approx 4589.4$ & $\approx 4032.4$ \\
\hline 11. & $\begin{array}{l}\text { Calculation of } \\
P_{c b w}[\mathrm{~W}] .\end{array}$ & $\approx 5048.4$ & $\approx 4435.6$ \\
\hline 12. & $\begin{array}{c}\text { Calculation of } \\
P_{s p b}[\mathrm{~W}] .\end{array}$ & $\approx 4796$ & $\approx 4214$ \\
\hline
\end{tabular}

The input data are as follows: the heaviest cutting regime of operation - at unalloyed steel and aluminium alloys, respectively with $H_{B}=125$ and $H_{B}=60$; $D_{m b \max }=0.05 \mathrm{~m} ; D_{c b \max }=0.035 \mathrm{~m} ; \eta_{b}=0.85$, $K_{\text {spg }}=1.3$ and $a_{p b \max }=0.003 \mathrm{~m}$. The respective results obtained are given in Table 1.

Boring operation modes can be as follows: singleedge cuts, multi- edge cuts, step- boring, reaming.

The choice of boring tools goes through the following several stages: definition of the operation type; selection of a boring system; definition of the boring diameter and hole requirements; choosing of the entering angle; selection of an adaptor; selection of inserts for the tools.

The calculations performed according to the presented methodology have the same input data for materials of different hardness, in order to compare and analyze the obtained results.

The selected motors must have power about 10\% greater than the calculated one, in order to compensate for the allowable wear over time. These obtained values are used for the motor choice from the respective technical catalogs.

Table 2. Parameters of the selected spindle drives.

\begin{tabular}{|c|c|c|}
\hline Parameters & $\begin{array}{c}\text { In machining of } \\
\text { unalloyed steel }\end{array}$ & $\begin{array}{c}\text { In machining of } \\
\text { aluminium alloys }\end{array}$ \\
\hline $\begin{array}{c}\text { - electric } \\
\text { motor }\end{array}$ & $\begin{array}{c}\text { DC motor MP112SL } \\
P=7.5 \mathrm{~kW}\end{array}$ & $\begin{array}{c}\text { AC motor DW: } \\
P=7.2 \mathrm{~kW},\end{array}$ \\
\hline $\begin{array}{c}\text { - power } \\
\text { convertor }\end{array}$ & model SA-12 & model KW8 \\
\hline
\end{tabular}

As a result of the calculations made for these two materials, appropriate DC and AC electric drives were chosen from $[14,15,18]$. Some of their basic parameters are presented in Table 2.

\section{Experimental studies}

A stand for experimental research of electric drives for machine tools has been developed, equipped with the necessary measuring and visualization devices.

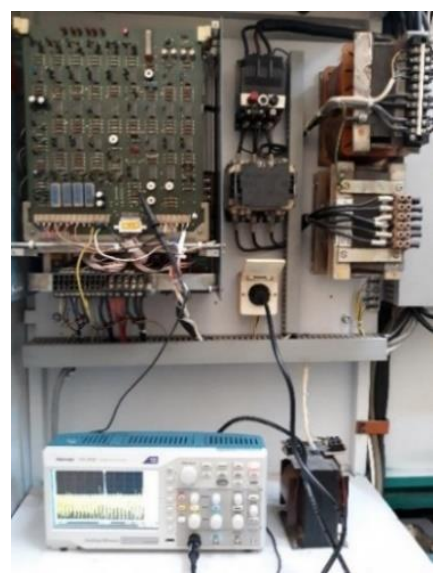

Fig. 4. Experimental study of a dual-zone DC motor drive. 
Based on the formulated requirements, the developed methodology, the calculations performed, and the selected electric drives, detailed experimental studies were carried out at different operating modes and settings of the respective controllers.

Fig. 4 illustrates the experimental study of a dualzone spindle electric drive for boring machines.

Fig. 5 shows a modernized instruments drive, where the following indications are used: 1 - induction motor for instruments drive; 2 - sensor for selection of position; 3 - springs; 4 - pins; 5 - hydraulic cylinder; 6 instruments; 7 - hydraulic valves; 8 - sensor used for control of instrument drive from developed ladder diagram.

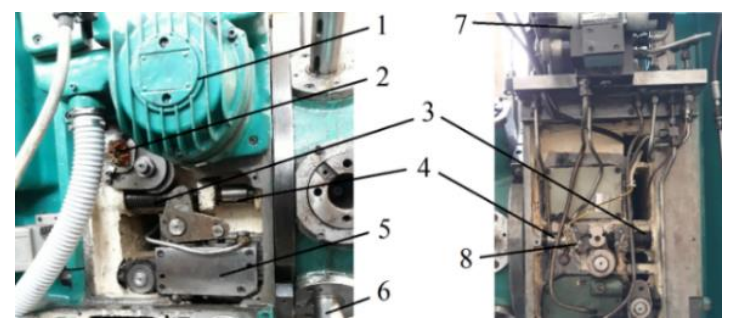

Fig. 5. A modernized instruments drive.

The following figures present some oscillograms obtained for the implemented DC, synchronous and induction drives in the studied class of machine tools.

Fig. 6 shows time diagrams obtained experimentally for both zones of speed regulation for a DC drive at different reference speeds and tuning of the control loops. Fig. $6 a$ presents a time diagram for the first speed zone with direct reverse. In this case, the reference speeds are $60 \mathrm{rad} / \mathrm{s}$ and $-60 \mathrm{rad} / \mathrm{s}$, respectively. Fig. $6 b$ shows a time diagram for the second zone at different working speeds.
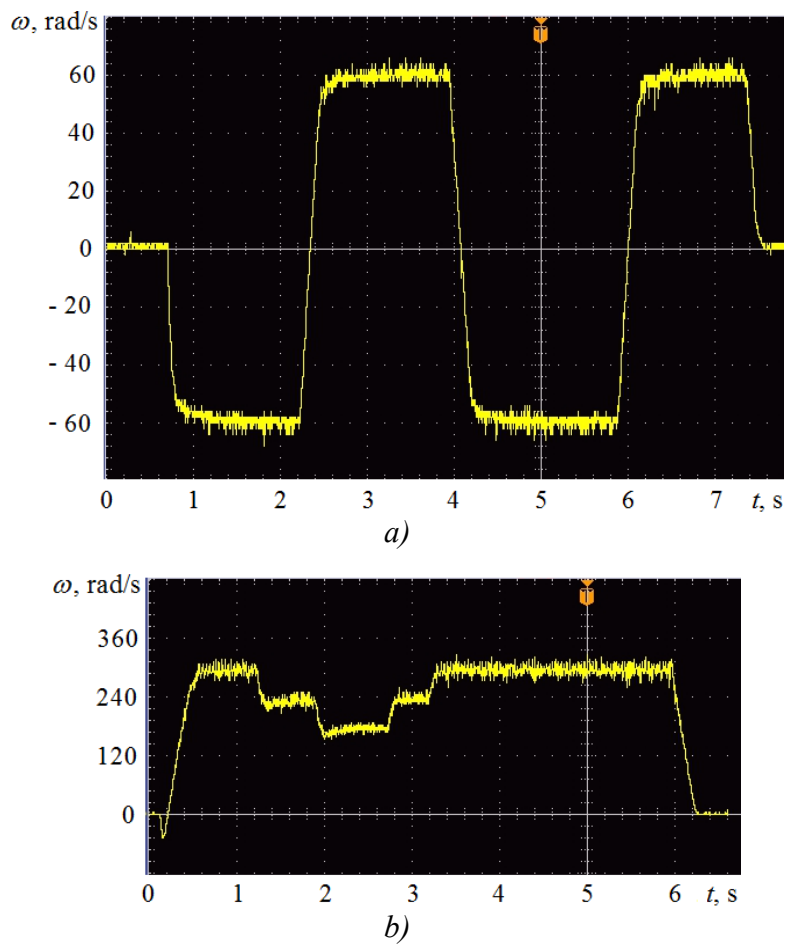

Fig. 6. Time diagrams for spindle drive with DC motor.
Fig. 7 presents a time diagram of the speed for synchronous motor spindle drive with reference value of $104.67 \mathrm{rad} / \mathrm{s}$.

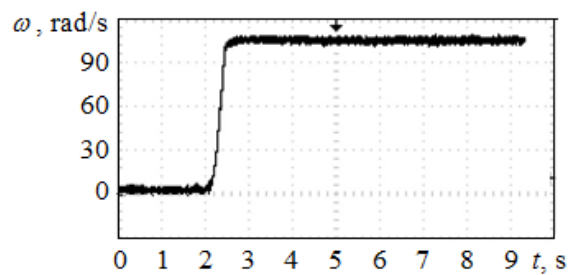

Fig. 7. Diagram for spindle drive with synchronous motor.

Fig. 8 shows an experimentally obtained time diagram for induction motor drive with vector control. The velocity feedback signal [V] is displayed as a function of the time [s] and the set value in this case is $41.89 \mathrm{rad} / \mathrm{s}$.

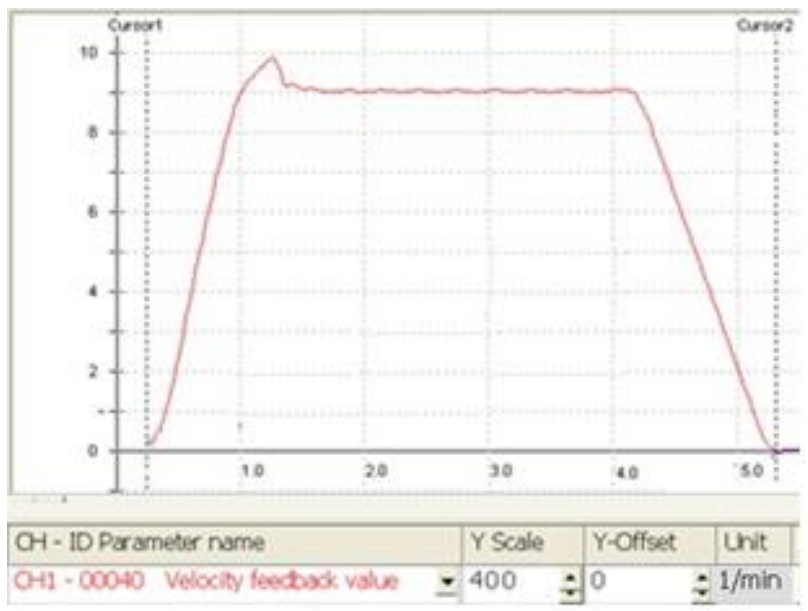

Fig. 8. Experimentally obtained speed time diagram for spindle drive with an induction motor.

Based on the studies carried out with various DC and $\mathrm{AC}$ electric drives the following practical inferences can be drawn:

- The implemented DC motors have very good tuning qualities and provide the necessary static and dynamic characteristics for spindle drives. Their disadvantage is the presence of the brush collector.

- Electric drives with AC motors have easier operational maintenance however their price is relatively higher.

\section{Conclusion}

The main features of the drive system for a type of boring machines with digital program control are analyzed and formulated. On this basis, a methodology for optimal selection of spindle drives is offered. The developed algorithm takes into account the technological process, the treated materials, the tools used and the mechanical gear.

Examples for choice of spindle electric drives with DC and AC motors are shown, illustrating the practical application of the described methodology. 
Experimental studies with the selected spindle drives are presented and discussed. The analysis of their dynamic and static regimes of operation showed that such drives could ensure good performance.

The research held as well as the results obtained can be used in the development, optimization and tuning of such dual-zone electric drives for the studied class of machine tools.

This work is supported by the Technical University of Sofia, Bulgaria under Research Project No. 191PR0002-08/2019.

\section{References}

1. G. Boothroyd, W. A. Knight, Fundamentals of Metal Machining and Machine Tools (CRC Press, 2005).

2. D. A. Stephenson, J. S. Agapiou, Metal Cutting, Theory and Practice (CRC Press, 2006).

3. H. Youssef, H. El-Hofy, Machining Technology: Machine Tools and Operations (CRC Press, 2008).

4. P. N. Rao, Metal cutting and Machine Tools (McGraw Hill Education, 2013).

5. I. P. Girsang, J. S. Dhupia, Machine tools for machining, (Springer-Verlag, 2015).

6. M. Zhilevski, M. Mikhov, T., Optimal selection of feed drives for boring machines, IOP Conference Series: Materials Science and Engineering (to be published).

7. M. Mikhov, M. Zhilevski, Analysis of a MultiCoordinate Drive System Aiming at Performance Improvement, Proceedings of the International Conference "Research and Development in Mechanical Industry", 2, pp. 1102-1107 (SaTCIP, Vrnjacka Banja, Serbia, 2012).

8. M. Zhilevski, M. Mikhov, Performance Improvement of a Type of Turning Machines, European Journal of Engineering Research and Science, 3, No. 8, pp. 44-49 (2018).

9. G. Popov, T. Geshev, Technical Possibilities for Diagnoses of Kinematic System of Machine Tools, Based on IEC 61499 Standard, VIII International Scientific Congress "Machines, Technologies, Materials”, 2, pp. 127-130 (2011).

10. T. Geshev, G. Popov, Mathematical Models for Diagnoses of Kinematic System of Machine Tools, Based on IEC 61499 Standard, VIII International Scientific Congress "Machines, Technologies, Materials”, 2, pp. 131-133 (2011).

11. M. Mikhov, B. Balev, Modeling and optimization of an electric drive system with dual-zone speed regulation, Proceedings of the International Conference on Communication and Energy Systems and Technologies, pp. 575-578, (UNIGRAF, Nish, Serbia, 2005)

12. M. Mikhov, T. Georgiev, An Approach to Synthesis of a Class of Electric Drives with Dual-Zone Speed control, Advances in Electrical and Computer Engineering, 10, No. 4, pp. 87-94 (2010).
13. M. Mikhov, M. Zhilevski and A. Spiridonov, Modeling and Performance Analysis of a Spindle Electric Drive with Adaptive Speed Control, Journal Proceedings in Manufacturing Systems, 7, No. 3, pp. 153-158 (2012).

14. AMKASYN, AC Servo- and Main Spindle Motors, (AMK Catalogue, 2014).

15. AMKASYN, Servo Drives $K E / K W$, (AMK Catalogue, 2014).

16. Sandvik Coromant, Metalcutting Technical Guide: Turning, Milling, Drilling, Boring, Toolholding, (Sandvik, 2005).

17. Andonov I., Cutting of Metals, (Softtrade, Sofia, 2001).

18. SERVOMOTORS, Gama Motors (Catalogue, 2016). 